PREPARED FOR THE U.S. DEPARTMENT OF ENERGY, UNDER CONTRACT DE-AC02-76CH03073

PPPL-3513

PPPL-3513

UC-70

Overview of the Initial NSTX Experimental Results

by

M. Ono and the NSTX Team

November 2000

N/Princeton pinsma

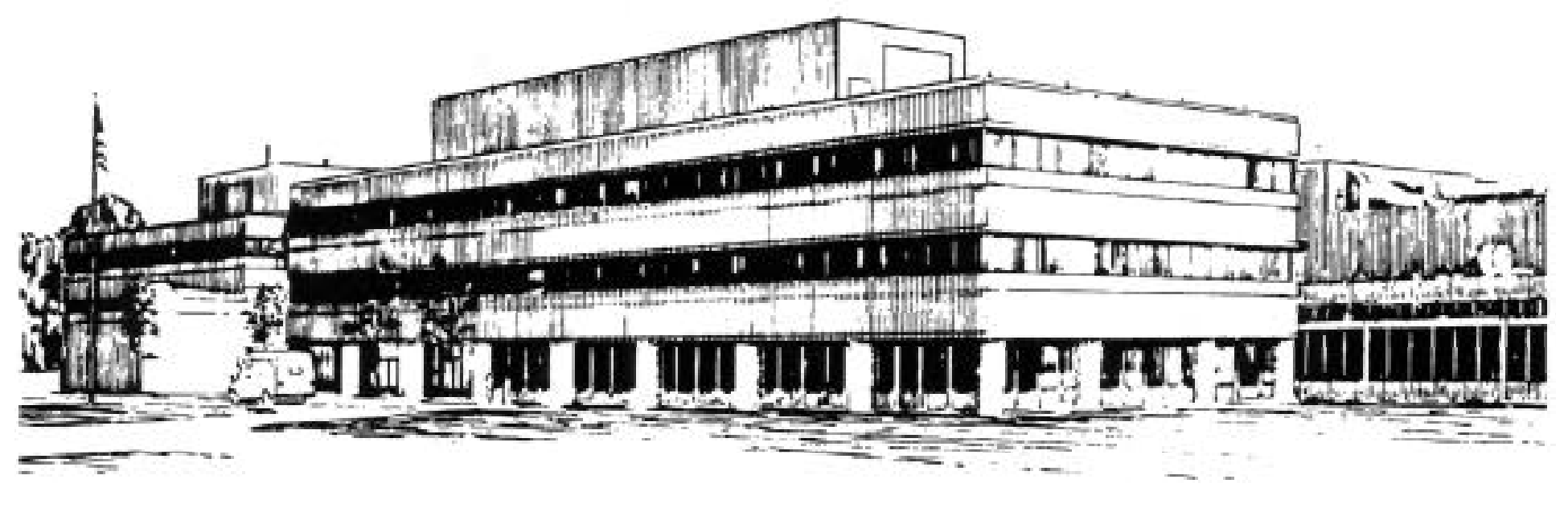

PRINCETON PLASMA PHYSICS LABORATORY PRINCETON UNIVERSITY, PRINCETON, NEW JERSEY 


\section{PPPL Reports Disclaimer}

This report was prepared as an account of work sponsored by an agency of the United States Government. Neither the United States Government nor any agency thereof, nor any of their employees, makes any warranty, express or implied, or assumes any legal liability or responsibility for the accuracy, completeness, or usefulness of any information, apparatus, product, or process disclosed, or represents that its use would not infringe privately owned rights. Reference herein to any specific commercial product, process, or service by trade name, trademark, manufacturer, or otherwise, does not necessarily constitute or imply its endorsement, recommendation, or favoring by the United States Government or any agency thereof. The views and opinions of authors expressed herein do not necessarily state or reflect those of the United States Government or any agency thereof.

\section{Availability}

This report is posted on the U.S. Department of Energy's Princeton Plasma Physics Laboratory Publications and Reports web site in Calendar Year 2000. The home page for PPPL Reports and Publications is: http://www.pppl.gov/pub_report/

DOE and DOE Contractors can obtain copies of this report from:

U.S. Department of Energy

Office of Scientific and Technical Information

DOE Technical Information Services (DTIS)

P.O. Box 62

Oak Ridge, TN 37831

Telephone: (865) 576-8401

Fax: (865) 576-5728

Email: reports@adonis.osti.gov

This report is available to the general public from:

National Technical Information Service

U.S. Department of Commerce

5285 Port Royal Road

Springfield, VA 22161

Telephone: $1-800-553-6847$ or

(703) $605-6000$

Fax: (703) 321-8547

Internet: http://www.ntis.gov/ordering.htm 


\title{
Overview of the Initial NSTX Experimental Results
}

\begin{abstract}
M. Ono 1), M. Bell 1), R. E. Bell 1), T. Bigelow 2), M. Bitter 1), W. Blanchard 1), D. Darrow1), E. Fredrickson 1), D. Gates 1), L. Grisham 1), J. Hosea 1), S. M. Kaye 1), R. Kaita 1), S. Kubota 9), H. Kugel 1), D. Johnson 1), B. Leblanc 1), R. Maingi 2), R. Maqueda 5), E. Mazzucato 1), J. Menard1), D. Mueller 1), B. A. Nelson 4), C. Neumeyer 1), F. Paoletti 3), S. Paul 1), Y-K.M. Peng 2), S. Ramakrishnan 1), R. Raman 4), P. Ryan 2), S. Sabbagh 3), C. Skinner 1), T. Stevenson 1), D. Stutman 7), E. Synakowski 1), D. Swain 2), G. Taylor 1), A. Von Halle 1), J. Wilgen 2), M. Williams 1), J.R. Wilson 1), R. Ackers 19), R.E. Barry 2), A. Bers 12), J. Bialek 3), P. Bonoli 12), M. D. Carter 2), J. Chrzanowski 1), W. Davis 1), E. Doyle 9), L. Dudek 1), R. Ellis 1), P. Efthimion 1), J. Ferron 6), E. Fredd 1), M. Finkenthal 7), T. Gibney 1), R. Goldston 1), R. E. Hatcher 1), R. Hawryluck 1), H. Hayashiya 14), K. Hill 1), T. Jarboe 4), S. C. Jardin 1), H. Ji 1), M. Kalish 1), L. Lao 6), K.C. Lee 11), F. Levinton 14), N.C. Luhmann 11), P. Lamarche 1), B. Mccormack 1), R. Majeski 1), J. Manickam 1), R. Marsala 1), T. K. Mau 10), S. Medley 1), M.M. Menon 2),O. Mitarai 17), M. Nagata 18), N. Nishino 16), G. Oliaro 1), H. Park 1), R. Parsells 1), T. Peebles 9), G. Pearson 1), C.K. Phillips 1), R. Pinsker 6), G.D. Porter 13), A.K. Ram 12), J. Robinson 1), P. Roney 1), L. Roquemore 1), A. Rosenberg 1), M. Schaffer 6), S. Shiraiwa 15), P. Sichta 1), B. Stratton 1), D. Stotler 1), Y. Takase 15), W. R. Wampler 8), G. Wurden 5), J. G. Yang 20), X. Q. Xu 13). L. Zeng 9), W. Zhu 3), S. Zweben 1)
\end{abstract}

1) Princeton Plasma Physics Laboratory, Princeton, NJ, USA

2) Oak Ridge National Laboratory, Oak Ridge, TN, USA,

3) Columbia University, New York, NY, USA

4) University of Washington, Seattle, WA, USA

5) Los Alamos National Laboratory, Los Alamos, NM, USA

6) General Atomics, San Diego, CA, USA

7) Johns Hopkins University, Baltimore, MD, USA

8) Sandia National Laboratory, New Mexico, USA

9) UC Los Angeles, Los Angeles, CA, USA

10) UC San Diego, San Diego, CA, USA

11) UC Davis, Davis, CA, USA

12) Massachusetts Institute of Technology, Cambridge, MA, USA

13) Lawrence Livermore National Laboratory, Livermore, CA, USA

14) Fusion Physics, and Technology, San Diego, CA, USA

15) Univ. Tokyo, Tokyo, Japan

16) Hiroshima Univ., Hiroshima, Japan

17) Kyushu Tokai Univ., Kumamoto, Japan

18) Himeji Inst. Technology, Okayama, Japan

19) EURATOM/UKAEA. Culham, UK

20) Korea Basic Science Institute, Taejeon, Korea

e-mail contact of main author: mono@pppl.gov

\begin{abstract}
The main aim of the National Spherical Torus Experiment (NSTX) is to establish the fusion physics principles of the spherical torus (ST) concept. The NSTX device began plasma operations in February 1999 and the plasma current $I_{p}$ was successfully brought up to the design value of 1 million amperes on December 14 , 1999. The planned plasma shaping parameters, $\kappa=1.6-2.2$ and $\delta=0.2-0.4$, were achieved in inner limited, single null and double null configurations. The CHI (Coaxial Helicity Injection) and HHFW (High Harmonic Fast Wave) experiments were also initiated. A CHI injected current of $27 \mathrm{kA}$ produced up to $260 \mathrm{kA}$ of toroidal current without using an ohmic solenoid. With an injection of 2.3 MW of HHFW power, using twelve antennas connected to six transmitters, electrons were heated from a central temperature of $400 \mathrm{eV}$ to $900 \mathrm{eV}$ at a central
\end{abstract}


density of $3.5 \times 10^{13} \mathrm{~cm}^{-3}$ increasing the plasma energy to $59 \mathrm{~kJ}$ and the toroidal beta, $\beta_{\mathrm{T}}$ to $10 \%$. Finally, the NBI system commenced operation in Sept. 2000. The initial results with two ion sources $\left(\mathrm{P}_{\mathrm{NBI}}=2.8 \mathrm{MW}\right)$ shows good heating, producing a total plasma stored energy of $90 \mathrm{~kJ}$ corresponding to $\beta_{\mathrm{T}} \approx 18 \%$ at a plasma current of 1.1 MA.

\section{Motivation and mission of NSTX}

A broad range of encouraging advances have been made in the exploration of the Spherical Torus (ST), a very low aspect-ratio tokamak concept [1]. A schematic of the ST magnetic configuration is shown in Fig. 1. These advances include promising experimental data from pioneering experiments [2-4], theoretical predictions [5,6], near-term fusion energy development projections such as the Volume Neutron Source [7], and future applications to power plants [8]. The National Spherical Torus Experiment (NSTX) is a U.S. national research facility located at the Princeton Plasma Physics Laboratory (PPPL). Its focus is on ST related research with an emphasis on finding a cost-effective route to an attractive fusion power plant. NSTX's main mission is to extend the understanding of toroidal plasma physics to new regimes at the mega-ampere level at high plasma beta $[9,10]$. The key physics objective of NSTX is to attain an advanced ST regime; i.e., simultaneous ultra high beta $(\beta)$, high confinement, and high bootstrap current fraction $\left(f_{b s}\right)[6]$. This regime is considered essential for the development of an economical power plant because it minimizes the recirculating power and power plant core size. Other NSTX mission elements crucial for ST power plant development are the demonstration of fully non-inductive operation and the development of acceptable power and particle handling concepts.

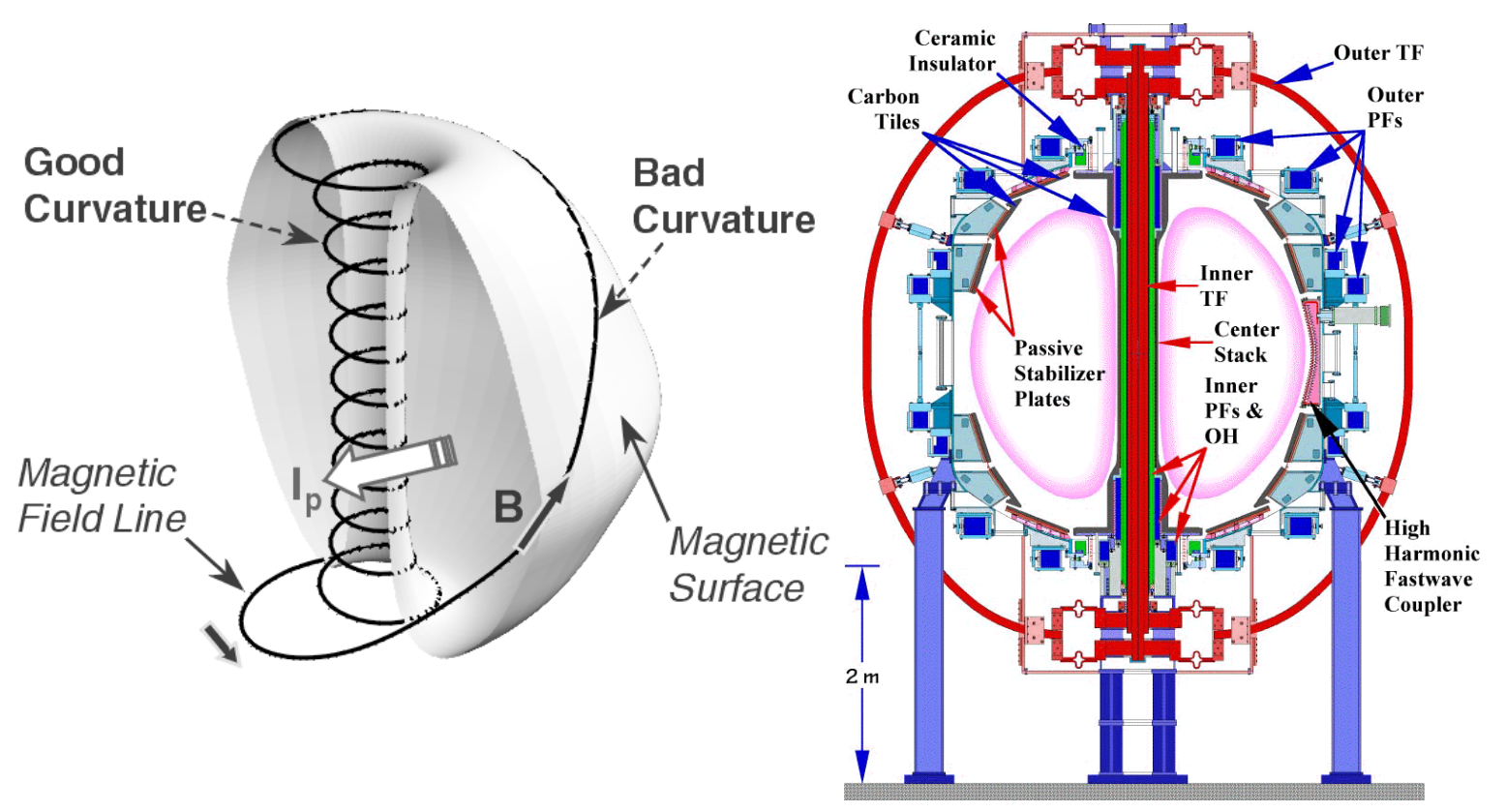

Fig. 1. The ST Configuration maximizes the field line length in the region of favorable

Fig. 2. NSTX Device Cross Section curvature.

\section{NSTX Facility Design Capability and Technology Challenges}

The NSTX facility [11] is designed to achieve the NSTX mission with the following capabilities:

- $\mathrm{R} / \mathrm{a} \geq 1.26$, including a 0.6 Weber $\mathrm{OH}$ solenoid and coaxial helicity injection $(\mathrm{CHI})[4,12]$ for plasma startup 
- $\mathrm{I}_{\mathrm{p}}=1$ MA for low collisionality at relevant densities

- High Harmonic Fast Wave [13] (HHFW - 6 MW, 5 s), Coaxial Helicity Injection (CHI $-\mathrm{I}_{\text {inj }} \leq 50 \mathrm{kA}$ at $1 \mathrm{kV}$ ), Neutral Beam Injection (NBI - $5 \mathrm{MW}, 5 \mathrm{~s}$ ) for heating and $\mathrm{j}(\mathrm{r})$ control

- Close-fitting conducting shell for maximum $\beta$ and $\beta_{\mathrm{N}}$

- Pulse length $5 \mathrm{~s} \geq$ skin time $\approx \mathrm{L} / \mathrm{R}$ time

The NSTX device is schematically shown in Fig. 2. The NSTX device/plasma configuration allows for strong plasma shaping, e.g., $I_{p} q_{95} / a B$ and can reach as high as 60, an order of magnitude greater than that achieved in conventional aspect-ratio tokamaks. The demountable center stack [composed of the inner toroidal field (TF) coil bundle, the Ohmic heating $(\mathrm{OH})$ solenoid, the poloidal field (PF) coils PF-1a and $-1 \mathrm{~b}$, thermal insulation, the Inconel vacuum casing, and the graphite plasma facing components with over 200 sensor elements] is the most critical component of NSTX [14]. The center stack is isolated from the outer vessel by ceramic insulators and bellows to provide electrical isolation for $\mathrm{CHI}$ and mechanical isolation to allow for the growth of the center-stack with respect to the outer vacuum vessel during bakeout and operations. The demountable center stack facilitates the construction, maintenance and/or future upgrading of the device. The NSTX device is equipped with closely-fitting $1.2 \mathrm{~cm}$ thick copper passive stabilizing plates for MHD mode stabilization. CHI and HHFW will be used for the initial plasma start-up studies. An innovative design was developed for the 12 element HHFW antenna decoupler / matching system powered by $6 \mathrm{RF}$ transmitters providing a total power of $6 \mathrm{MW}$ for up to $5 \mathrm{~s}$. One of the TFTR NBI systems (with three ion sources) is installed to inject a total power of $5 \mathrm{MW}$ at $80 \mathrm{kV}$ for up to $5 \mathrm{~s}$. Indeed, the NSTX facility utilizes much of the former TFTR facility at PPPL. After three years of design and construction, NSTX became operational in Feb. 1999.

\section{Progress on Ohmic Operations}

3.1 First Plasma and Achievement of 1 MA Plasma Current Discharges - On Feb. 12 1999, a fast camera observed the first "flash" of ohmic plasma with about $20 \mathrm{kA}$ of plasma current. Within the following two days of plasma operations, the plasma current reached the $300 \mathrm{kA}$ level, which is close to the predicted value for the $\mathrm{OH}$ flux used (about 1/3 of the design flux.) The device capability was increased relatively quickly, and on Dec. 16, 1999 the plasma current was raised to the device design value of 1MA. Key to the achievement of high current plasma discharges was the implementation of the real time plasma control system which controls the plasma radial and vertical positions as well as the plasma current [15].

An electron cyclotron heating preionization (ECH-P) system proved to be helpful in plasma initiation. The $18 \mathrm{GHz}$ unit is capable of delivering $30 \mathrm{~kW}$ of ECH-P power for $100 \mathrm{~ms}$. The ECH-P creates a vertically uniform plasma sheet at the electron cyclotron resonant layer (which is at $\mathrm{R}=42 \mathrm{~cm}$ ) for the nominal $3 \mathrm{kG}$ toroidal field at the vacuum vessel center of $\mathrm{R}=$ $85 \mathrm{~cm}$. The ECH-P makes the $\mathrm{OH}$ plasma initiation less sensitive to error fields, enhancing the operational flexibility. Another utilization of ECH-P is for the low gas pressure start-up of the Coaxial Helicity Injection (CHI). It is important for $\mathrm{CHI}$ to be able to operate in a sufficiently low neutral pressure range to be compatible with the ohmic operations. The ECH$\mathrm{P}$ helps breakdown even at low neutral fill pressure, aiding the CHI start-up.

3.2 Ohmic Plasma Equilibrium - In Fig. 3, a comparison of visible light emission from the plasma imaged at $1 \mathrm{kHz}[16]$ and the reconstructed plasma configuration (EFIT) with $1 \mathrm{~ms}$ resolution [17] are shown. The three frames are an early small-bore plasma, the transition to a lower single null diverted plasma, and the return to the center stack limited plasma, respectively. These features are all consistent with the details of the reconstructed plasma boundary shape. 

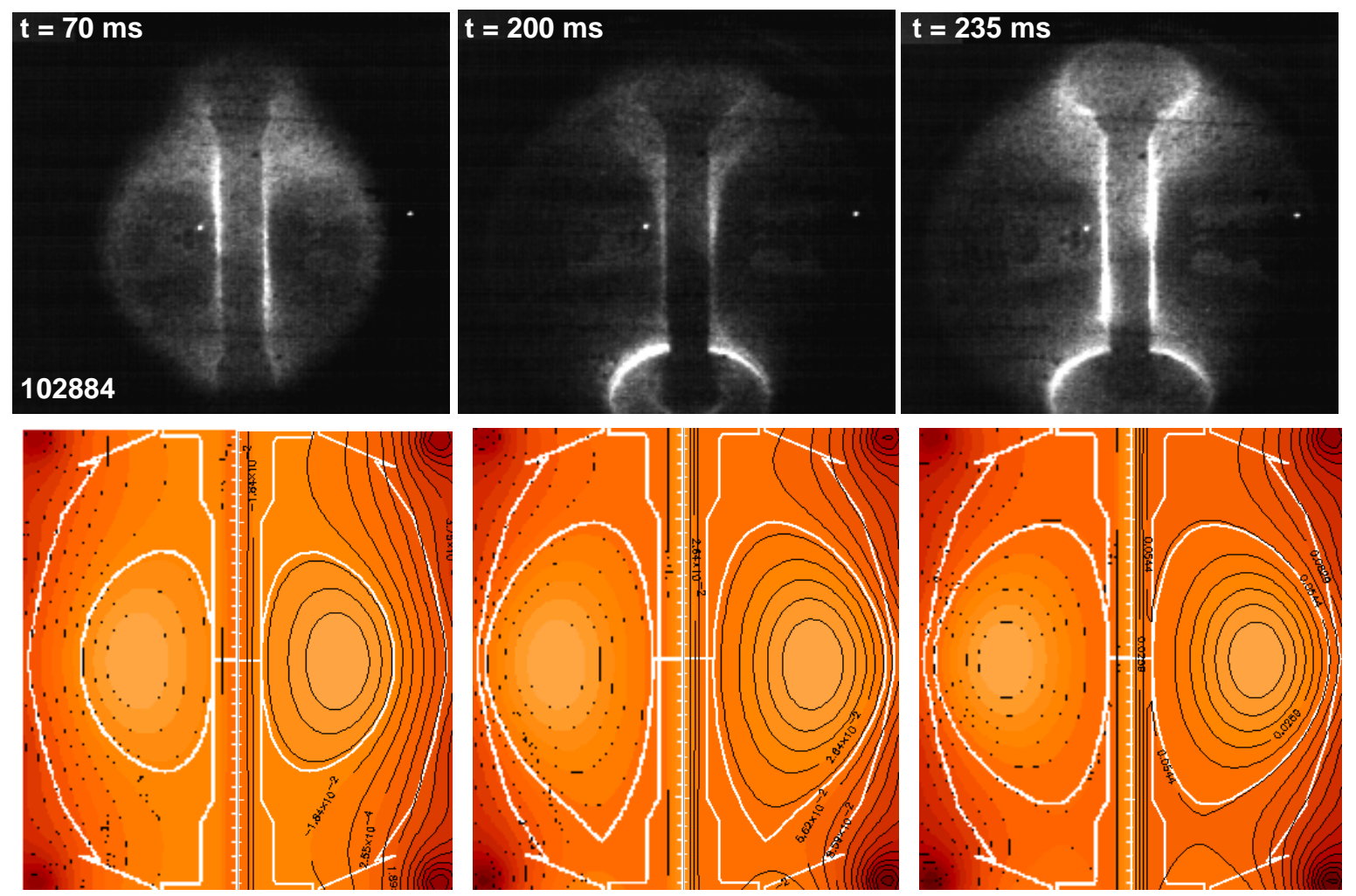

Fig. 3. Comparison of visible-light images of the evolution of the plasma boundary and EFIT magnetic reconstructions. The discharge time is as shown.

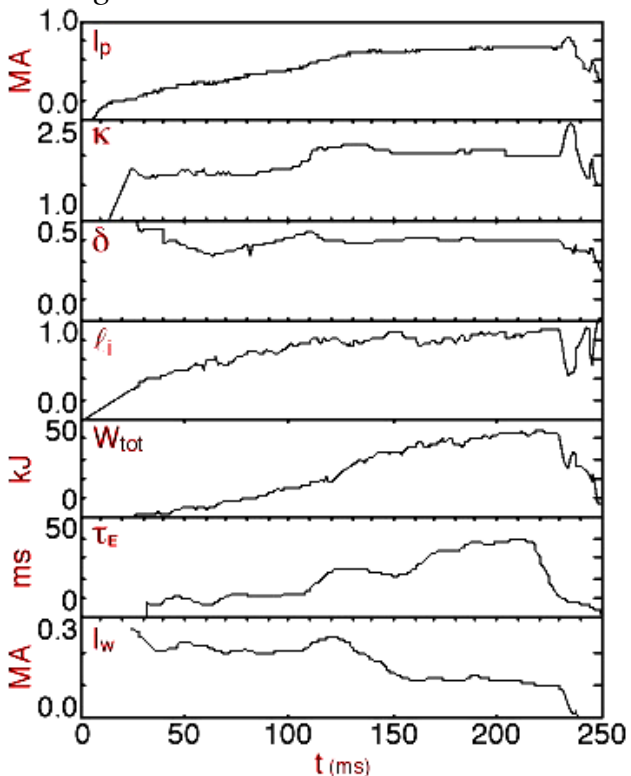

Fig. 4.: A typical plasma discharge evolution.

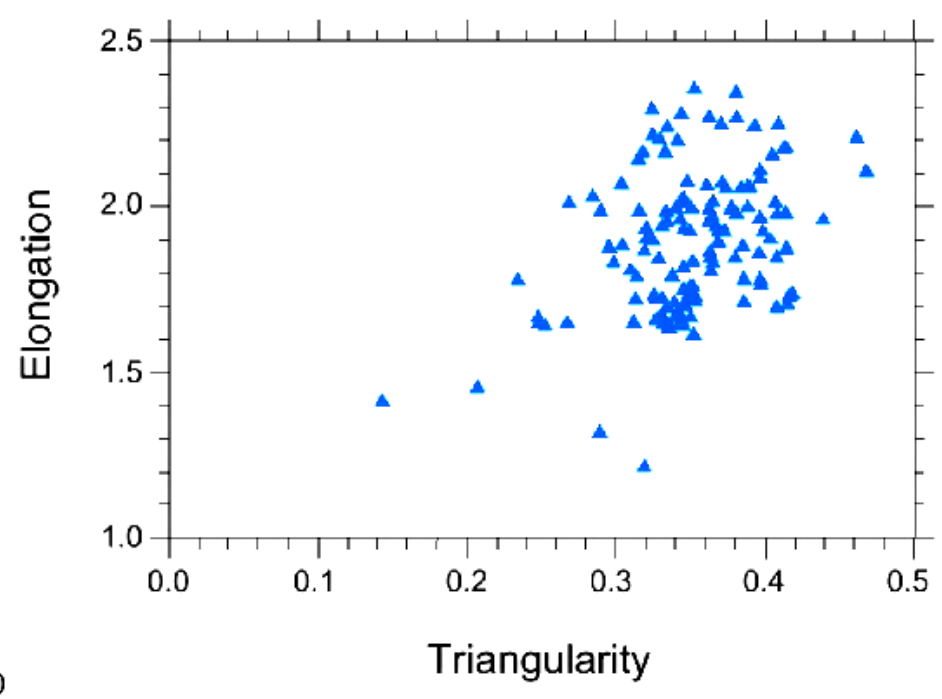

Fig. 5. Achieved plasma shaping parameters.

The $700 \mathrm{kA}$ level plasma evolution is shown in Fig. 4 where the plasma transiently reached an elongation of 2.5 and triangularity of 0.6 , with nominal flattop values of 2.0 and 0.4 respectively. Plasma internal inductance generally increases from 0.3 to $\sim 1.0$ during a discharge. A plasma shaping factor $\left(I_{p} q_{95} / a B\right)$ of 30 has been thus far achieved at 1 MA. Ohmic plasmas with volume in excess of $12 \mathrm{~m}^{3}$ have been routinely produced. The plasma configurations of inner wall limited, single null and double null diverted discharges were successfully created. Each configuration has been produced with a nominally constant plasma 
current for durations of 3 - 5 energy confinement times. The plasma shaping parameters accessed in the ohmic discharges are shown in Fig. 4 where the achieved elongation $\kappa$ and triangularity $\delta$ are plotted. These elongations and triangularities span much of the range of operating space expected from model calculations.

3.3 Ohmic Flux Consumption and Boronization - In order to optimize the ohmic flux consumption, various plasma current ramp-up rates have been investigated [18]. By convention, the resistive flux consumption is parameterized with the Ejima coefficient $C_{E}$ and the total surface flux consumption is parameterized here using the Ejima-Wesley coefficient $\mathrm{C}_{\mathrm{E}-\mathrm{w}}[18,19]$. Application of a boron coating on the plasma facing components using a glow discharge in a mixture of trimethylboron (TMB) and helium has significantly reduced the metallic and oxygen impurity level in NSTX plasmas. In Fig. 6, comparison shots before and after boronization are shown. The boronization not only reduced the loop-voltage and ohmic flux consumption, thus extending the pulse length, but it also reduced the MHD activity (Fig. 4). Figure 7 plots Ejima coefficients and the internal inductance for discharges of varied ramp-rates, both pre- (dashed) and post- (solid) boronization in deuterium with line-average densities of 2-4 $\times 10^{13} \mathrm{~cm}^{-3}$ at peak current. The figure shows, as expected, that faster ramps reduce flux consumption by reducing both the resistive dissipation (a) and internal inductance (b). In practice, average ramp- rates of 5-6 MA/s are routinely obtained, while faster ramps become increasingly prone to MHD events. The total flux consumption during the ramp-up phase also dropped by $20 \%$ after boronization as shown in Fig. 7. Most of the decrease comes from a decrease in the internal inductance at fixed ramp-rate.

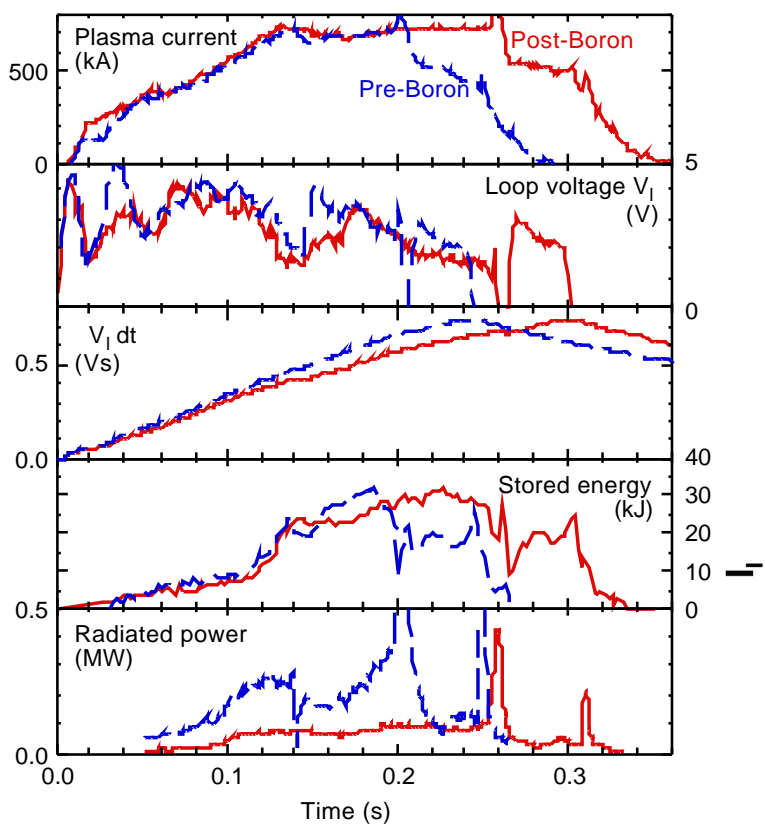

Fig. 6. Effect of boronization on the Ohmic discharges.

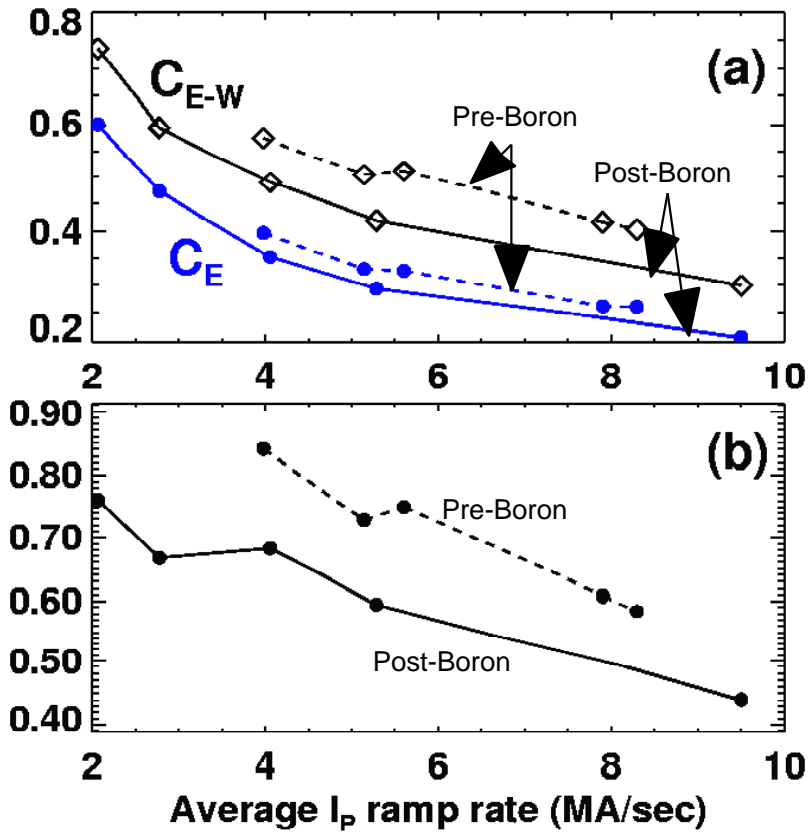

Fig. 7. (a) Ejima and Ejima-Wesley coefficient vs. ramp-rate. (b) Internal inductance vs. ramp-rate

3.4 Density Limits and Global Energy Confinement - The density limits and global energy confinement were investigated for the plasma current range of $600-900 \mathrm{kA}$. The density limits observed in NSTX generally improved over the time as the plasma conditions improved through wall conditioning. In particular, the TMB boronization improved the density operating range significantly as shown in Fig. 8. The effect of the boronization was to increase the achievable densities in both species. Densities (line averaged) greater than $4 \times 10^{19} \mathrm{~m}^{-3}$ were attained only in post-boronized helium plasmas. As shown in Fig. 9, the deuterium density limit increased from approximately $60 \%$ of the Greenwald limit density $\left(\mathrm{n}_{\mathrm{eGW}} \equiv \mathrm{I}_{\mathrm{p}} / \pi \mathrm{a}^{2}\right)$ for the pre-boronization level to about 75 to $80 \%$ of the limit, while the 
helium density limit increased from about $75 \%$ of the limit (pre-boronization) to the actual limit and even a bit beyond. The only MHD observed at the time of the density limit in the highest density cases were sawteeth, and investigations are underway to determine whether the limit is related to the sawteeth, or whether fueling limitations set the maximum density.

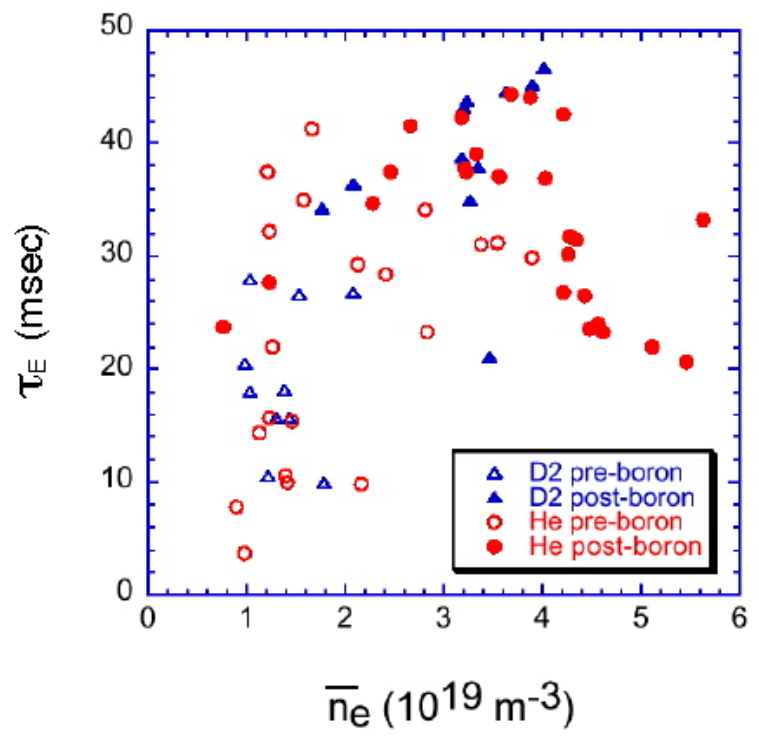

Fig. 8. Energy confinement time vs. plasma density. Ip $=600-900 \mathrm{kA}$

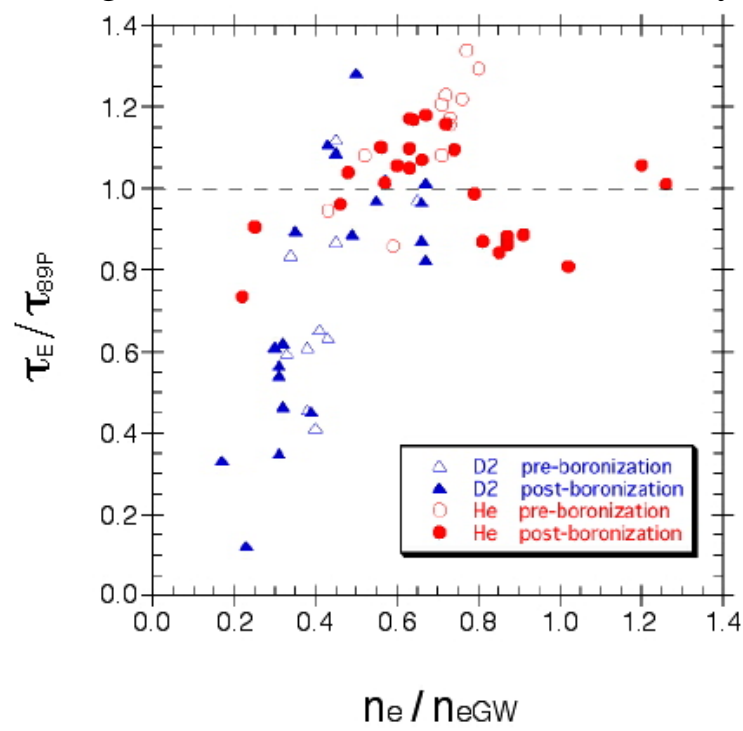

Fig. 9. ITER 89P normalized energy confinement time vs. Greenwald normalized plasma density.

Confinement times in both deuterium and helium ohmic plasmas exhibit trends that are similar to those at conventional aspect ratio and they are summarized in Figs. 8 and 9. For low to moderate densities $\left(\leq 4 \times 10^{13} \mathrm{~cm}^{-3}\right.$, corresponding to $\left.\mathrm{n}_{\mathrm{e}} / \mathrm{n}_{\mathrm{eGW}} \leq 0.8\right)$, the confinement time in both species increases approximately linearly with line-averaged density to a value of $45 \mathrm{~ms}$. At $\mathrm{n}_{\mathrm{e}} / \mathrm{n}_{\mathrm{eGW}} \leq 0.8$, the maximum confinement time is approximately $1.4 \tau_{\text {ITER 89P }}$, while $\tau_{\mathrm{E}} / \tau_{\text {ITER89P }}=0.8-1.0$ at the higher densities. The confinement time drops to values of about $20 \mathrm{~ms}$ at the highest density $\left(5.5 \times 10^{19} \mathrm{~m}^{-3}\right)$, corresponding to $\mathrm{n}_{\mathrm{e}} / \mathrm{n}_{\mathrm{eGW}} \leq 1.2$. For the ITER89P scaling used in Fig. 9, the mass scaling parameter was taken to be $\mathrm{M}_{\text {eff }} / \mathrm{Z}_{\text {ion }}$, which is 2 for either species. This is consistent with the observed similar confinement behavior for helium and deuterium discharges. One major difference between the deuterium and helium higher density discharges was the amount of carbon influx as indicated by the CIII light, which was much greater in deuterium plasmas presumably due to chemical sputtering of the graphite tiles. For both species, in both the pre- and post-boronized plasmas, the radiated power was typically $\leq 30 \%$ of the ohmic heating power at the time of maximum density.

3.5 MHD Activity - A variety of MHD activities including reconnection events and sawtooth activity are observed in NSTX. The reconnection events depend particularly strongly on the wall conditions. During the first plasma operations with the newly fabricated vacuum vessel and partial graphite-tile wall coverage, MHD activity was frequently observed throughout the discharge. As the discharge conditions improved, the frequency of the MHD events decreased. The complete graphite tile coverage together with wall conditioning (baking, glow discharge cleaning and boronization) all helped to reduce the frequency of the MHD events. MHD events occur particularly during the current ramp down phase. With an appropriate gas-puff, it is possible to ramp down without these events for some discharges. Presently, the dominant MHD mode appears to be the toroidal mode number $\mathrm{n}=1$ mode, though some higher $\mathrm{n}$ number and higher frequency modes have been observed. In Fig. 10(a), the plasma evolution illustrating the deleterious effect of a sawtooth is shown. A significant core pressure reduction occurs when the sawtooth activity starts. 

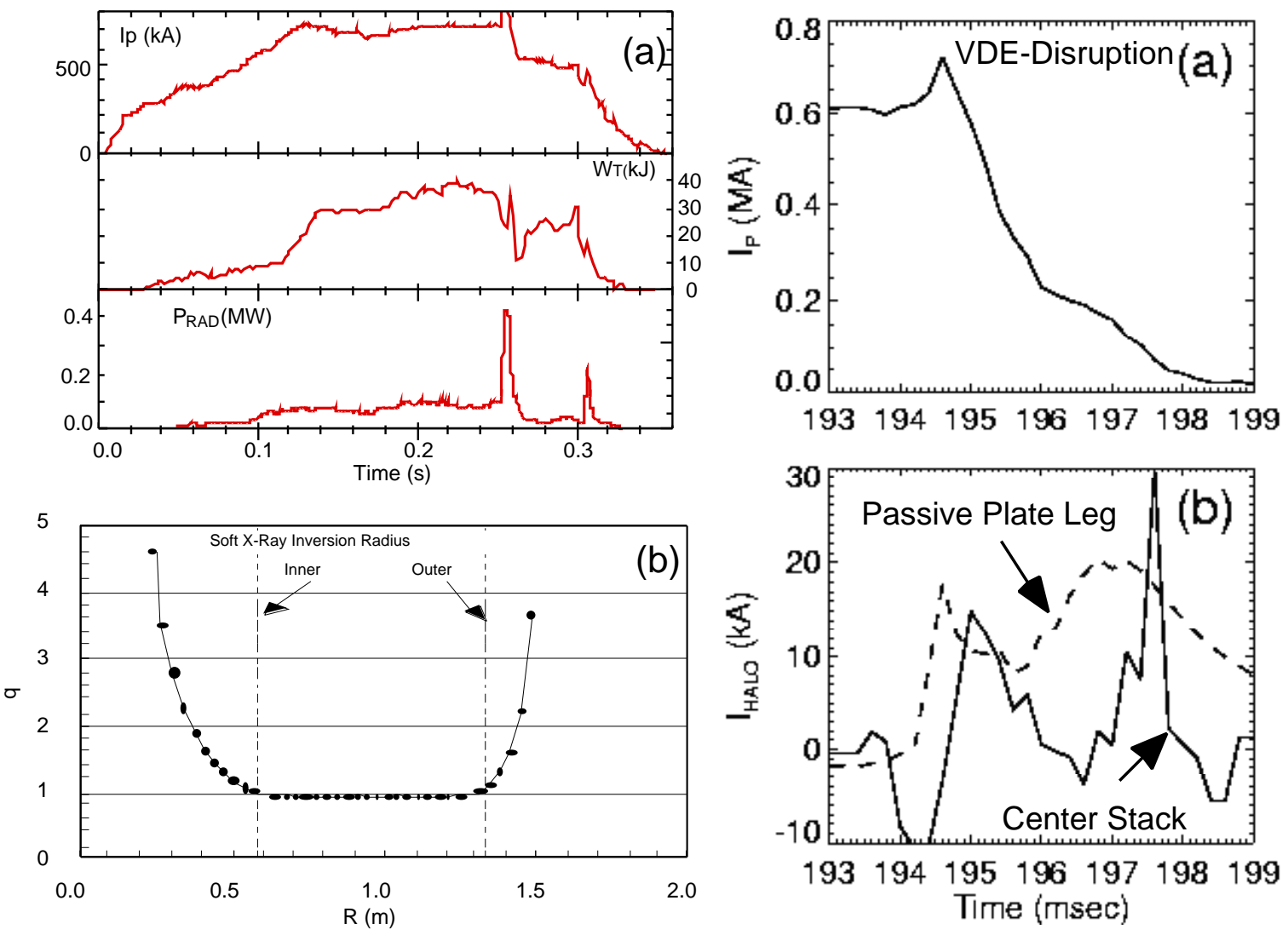

Fig. 10. MHD Behavior. (a) Ohmic discharge with a sawtooth crash. (b) EFIT q profile versus major radius and position of soft $x$-ray inversion radius.

Fig. 11. Disruption and halo-evolution with with induced currents. (a) Plasma current decay during disruption. (b) Wall- induced currents in the center stack (solid curve) and the passive plate leg (dashed curve).

From the EFIT magnetic reconstruction, the start of sawtooth activity coincides well with the appearance of the $\mathrm{q}_{0}=1$ surface as shown in Fig. 10(b). Due to the strong shaping and toroidicity (low-aspect-ratio) of NSTX, the EFIT reconstruction contains significant internal profile information, such as the pressure and q-profiles. The agreement between the soft $\mathrm{x}^{-}$ ray sawtooth inversion layer and $q=1$ surface is surprisingly good. As can be seen from the Fig. 10(b), due to the large radius position of the $\mathrm{q}=1$ layer, the sawtooth crash in NSTX causes significant degradation to the plasma performance by causing the central pressure to collapse. It is therefore quite clear that we must control the plasma current profile so that $\mathrm{q}_{0}$ stays well above 1 .

3.6 Plasma Disruptions and Wall Halo Currents - The plasma disruption and generation of wall halo currents remain critical issues for tokamak reactor designs due to the high stress on the wall and PFCs imparted by the $\mathrm{j}_{\mathrm{pol}} \times \mathrm{B}_{\mathrm{T}}$ force of the halo-induced wall currents. In the CDX-U and START devices, the plasma halo currents have been measured to be only a small fraction, below $5 \%$, of the peak plasma current $[2,3]$. Recent MAST results also support this rather benign trend for the ST [20]. On NSTX, halo currents have been measured in the center column as well as in the passive stabilizer plate support legs. While plasma disruptions (very rapid current terminations) can be avoided most of the time, it is prudent to design a fusion reactor, which could withstand disruptions. On NSTX, plasma disruptions are indeed observed. The fastest plasma current decays were observed during the so-called VDE (Vertical Displacement Event) due to a loss of vertical position control. In Fig. 11(a), a 
plasma disruption with the plasma current ramp-down rate of $400 \mathrm{MA} / \mathrm{s}$ (the fastest thus far observed) is shown. Figure 11(b) shows that the induced CS casing current (solid line) measured by a Rogowski coil located near the end of the center-stack has a peak magnitude of 20-30kA. This corresponds to 3-5\% of the maximum plasma current. Figure 11(b) also shows the toroidal current induced on the outboard lower primary passive plate peaks at approximately 10kA. These halo-induced wall currents are therefore relatively modest and benign from the device design point of view.

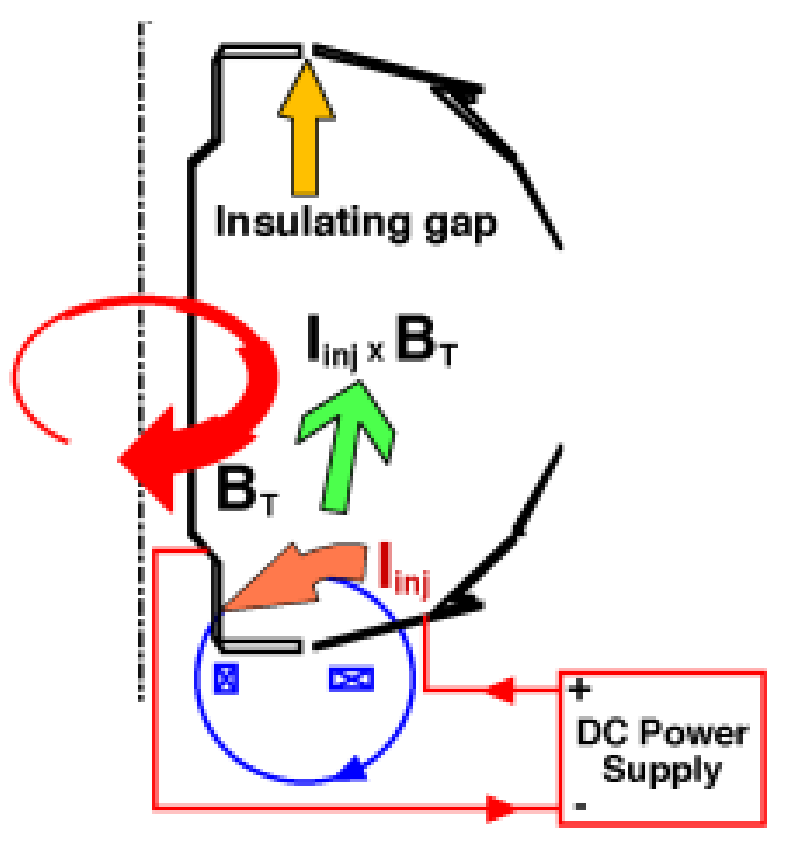

Fig. 12. Schematic of CHI Experimental setup.

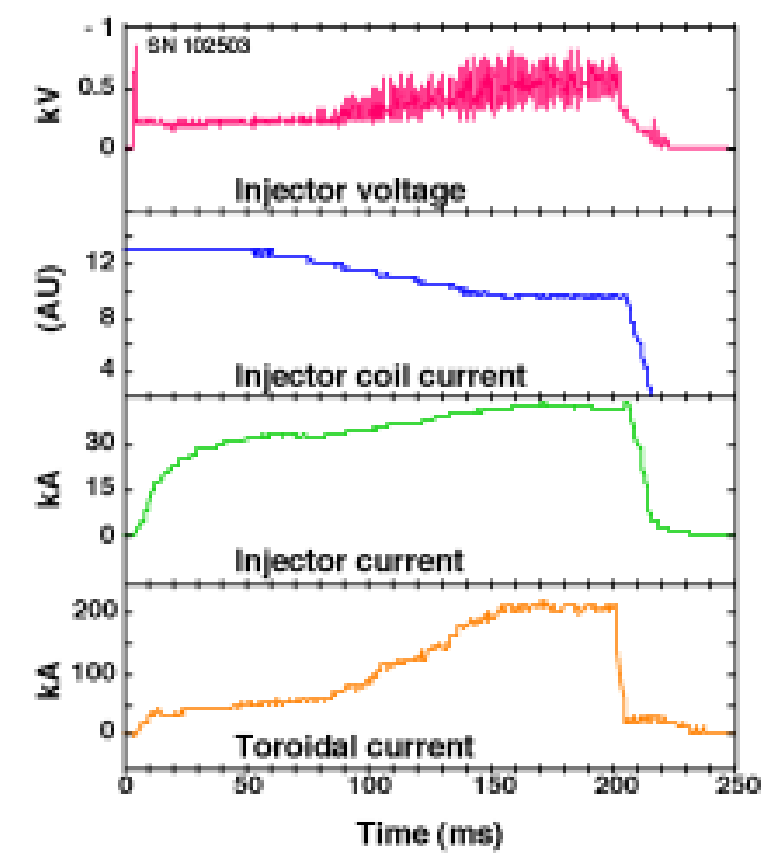

Fig. 13 CHI discharge evolution.

\section{Co-axial Helicity Injection Plasma Start-up}

For an attractive ST power plant, the $\mathrm{OH}$ solenoid must be eliminated in the center stack. The relatively modest magnetic flux and helicity per unit plasma current for ST tend to ease noninductive startup requirements. The main tool being tested for NSTX is the coaxialhelicity-injection (CHI). The concept has been investigated previously in smaller experimental devices including HIT/HIT-II [4] and HIST [12]. An experimental set-up of $\mathrm{CHI}$ is shown in Fig. 12. Because of the ceramic insulating rings located at the top and bottom of the device, the center-stack is electrically insulated from the outer vacuum vessel, allowing bias voltage to be applied. With appropriate gas fill pressure (typically in a few $\mathrm{m}$ Torr range) and with a voltage of up to $1 \mathrm{kV}$ applied, a plasma discharge is initiated. Here using appropriate poloidal field coils (as shown in Fig. 12), stronger poloidal fields are applied near the bottom gap, which reduces the connection length, so that the discharge is initiated preferentially in the lower gap region. The applied toroidal field causes the current in the plasma to develop a strong toroidal component, the beginning of the desired toroidal plasma current. If the injector current exceeds a threshold value, the resulting $\Delta \mathrm{B}_{\text {tor }}{ }^{2}$ or $\left(\mathbf{J}_{\mathrm{pol}} x\right.$ $\mathbf{B}_{\text {tor }}$ ) stress across the current layer exceeds the field line tension of the injector flux causing the helicity and plasma in the lower divertor region to move into the main torus chamber. It should be noted that the CHI system capability on NSTX is a significant extension of the previous $\mathrm{CHI}$ experiments in that the plasma volume and pulse length are increased by a factor of about 30 [21]. In Fig. 13, typical CHI discharge waveforms are shown in which the toroidal current is driven from zero current without the ohmic solenoid. The discharge has $200 \mathrm{~ms}$ pulse length with a flat top toroidal current of $200 \mathrm{kA}$. To date, CHI in NSTX has driven toroidal plasma currents of up to about $260 \mathrm{kA}$ transiently with injections of about 27 $\mathrm{kA}$, yielding current amplification factors of $\approx 10$. Our near term goal is to drive $\mathrm{a} \approx 500 \mathrm{kA}$ 
toroidal current with $50 \mathrm{kA}$ of injection current. The CHI capability thus developed on NSTX will be used to assist the current ramp-up to about $1 \mathrm{MA}$ and to provide edge current drive for current profile control. If the CHI plasma can be formed with about a $\mathrm{T}_{\mathrm{e}} \approx 200 \mathrm{eV}$, then it would be possible to heat and drive current in the start-up phase of the plasma by HHFW. This would go a long way toward realizing a fully non-inductive current start-up for an ST.

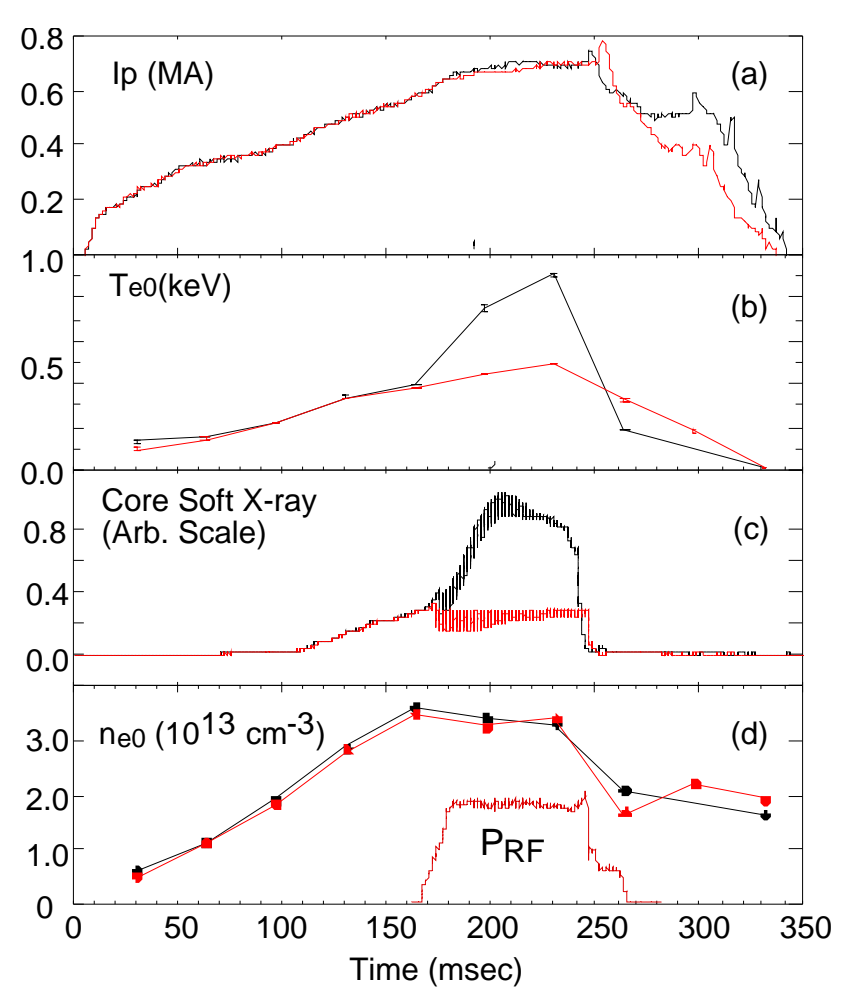

Fig. 14. Discharge evolution with and without $R F . P_{r f}=2.3 M W, k_{l l} \approx 14 m^{-1}, B_{T}=3 k G$, $\beta_{T}=10 \%, W_{T}=60 \mathrm{~kJ}, \varepsilon=40$

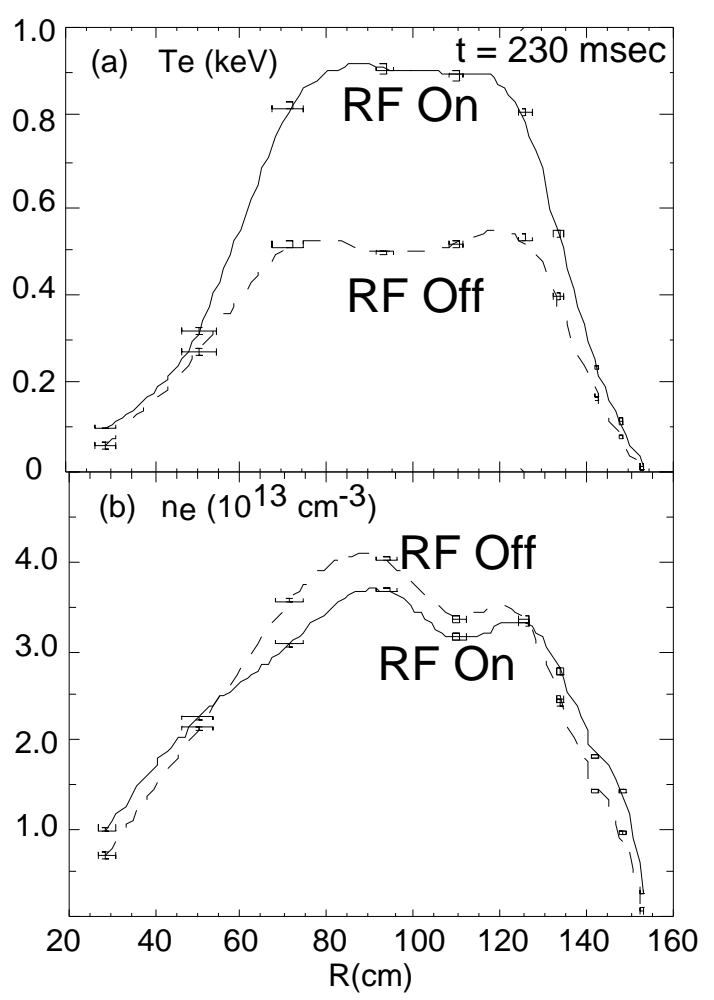

Fig. 15. Thomson scattering electron temperature and electron density.

\section{High Harmonic Fast Wave Heating}

High harmonic fast wave (HHFW) research is appropriate for NSTX due to its high beta and high plasma dielectric constant, $\varepsilon \equiv\left(\omega_{\mathrm{pe}} / \Omega_{\mathrm{e}}\right)^{2}$. For example, the NSTX plasmas typically operate in $\varepsilon=10-100$ range compared to the typical tokamak experiment of $\varepsilon \leq 1$. The central plasma toroidal beta in NSTX is well above $10 \%$ and is expected to reach the 50 $100 \%$ ranges. This requirement is similar to that in other compact confinement devices such as the Spheromaks, RFPs, and FRCs. In this regime, the conventional electron heating and current drive tools such as Electron Cyclotron Heating and Lower Hybrid Current Drive cannot be used due to the lack of wave accessibility. The HHFW is predicted to be able to access high dielectric plasmas and heat electrons efficiently via transit time magnetic pumping and electron Landau damping [8]. The NSTX antenna phasing system is capable of varying the $\mathrm{k}_{\| \mid}$from $14 \mathrm{~m}^{-1}$ to about $4 \mathrm{~m}^{-1}$ in real time in order to follow the plasma discharge evolution from low temperature $(\approx 300 \mathrm{eV})$ start-up plasmas to high temperature (few keV) high beta plasmas in real time [22].

The HHFW electron heating experiments thus far have concentrated on efficient coupling of power into the plasma with a known phase. Plasma currents from 500 to $700 \mathrm{kA}$ in helium and deuterium have been explored. Center stack limited and double null diverted discharges were employed. The outer gap was varied from essentially zero to $10 \mathrm{~cm}$ or more. A gap of around $5 \mathrm{~cm}$ was found to be optimal. Figure 14 shows the time evolution of a HHFW heated, $700 \mathrm{kA}$ helium plasma discharge where $2.3 \mathrm{MW}$ of HHFW power, with the slowest phasing (i.e., $\mathrm{k}_{\|} \approx 14 \mathrm{~m}^{-1}$ ), is applied starting at $160 \mathrm{~ms}$. In Fig. 15, the density and electron 
temperature profiles from Thomson scattering at $\mathrm{t}=230 \mathrm{~ms}$ are shown. The central electron temperature increases from $400-500 \mathrm{eV}$ to $900 \mathrm{eV}$ during the rf heating while the central density remains constant. The temperature increase is broad in radius and accompanied by little density increase. This is consistent with the slow-phase-velocity wave heating, where the heating deposition is expected to broaden as the central electron temperature is increased [22]. The loop voltage falls to $1.0 \mathrm{~V}$ as compared to $1.35 \mathrm{~V}$ on an identical plasma without rf. Confirmation of the temperature increase is also seen with an x-ray crystal spectrometer, which yields a central temperature of about $1 \mathrm{keV}$. The central plasma density was relatively constant at about $3.5 \times 10^{13} \mathrm{~cm}^{-3}$ corresponding to $\varepsilon \approx 40$. A maximum stored energy of $58 \mathrm{~kJ}$ and $\beta_{\mathrm{T}} \equiv 2 \mu_{0}<\mathrm{p}>/ \mathrm{B}_{\mathrm{T} 0}{ }^{2}=10 \%$ with $2.9 \mathrm{MW}$ of power was obtained. The HHFW electron heating has been observed with the ohmic plasmas with the electron temperature as low as $200 \mathrm{eV}$. Plasma radiation as measured by bolometry shows an increase in edge radiation, which is attributed to carbon. The total radiated power however remains very low at $<15 . \%$

\section{Initial Neutral Beam Heating Results}

6.1 NBI Heating Dependence on Plasma Current and Ion Source - A neutral beam injector (5 MW - $80 \mathrm{keV}$ ) from TFTR was installed on NSTX, and the system was commissioned in Sept 2000. The initial NBI heating experiment was conducted with two ion sources with a total power of up to $2.8 \mathrm{MW}$. The tangency radii of the two operating sources are Source B: $\mathrm{R}=50 \mathrm{~cm}$ and Source C: $\mathrm{R}=60 \mathrm{~cm}$. These are "off-axis" heating sources compared to the plasma axis at $\mathrm{R} \approx 90 \mathrm{~cm}$, as shown in Fig. 16 . At $80 \mathrm{keV}$, injected beam ions have a larger prompt orbit loss for lower plasma current as well as for Source $\mathrm{C}$ (compared to Source B) located more off-axis. In Fig. 17, the observed stored energy increase for a given source power of $\approx 1.4 \mathrm{MW}$ for Source $\mathrm{B}, \mathrm{C}$, and $\mathrm{B}+\mathrm{C}$ combined for various plasma currents is shown. The stored energy increment increases with the plasma current as expected. At $900 \mathrm{kA}$, the stored energy increment for two sources becomes comparable. As the current is decreased to $700 \mathrm{kA}$, the Source $\mathrm{C}$ shows a rapid decrease in heating efficiency, while Source B is still heating relatively well. At $500 \mathrm{kA}$, the heating efficiency for both sources drops dramatically, which is consistent with prompt orbit loss calculations [23].

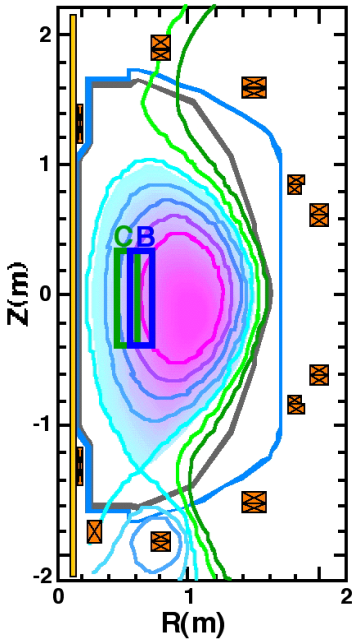

Fig. 16. NBI tangency foot prints for Sources $B$, and $C$.

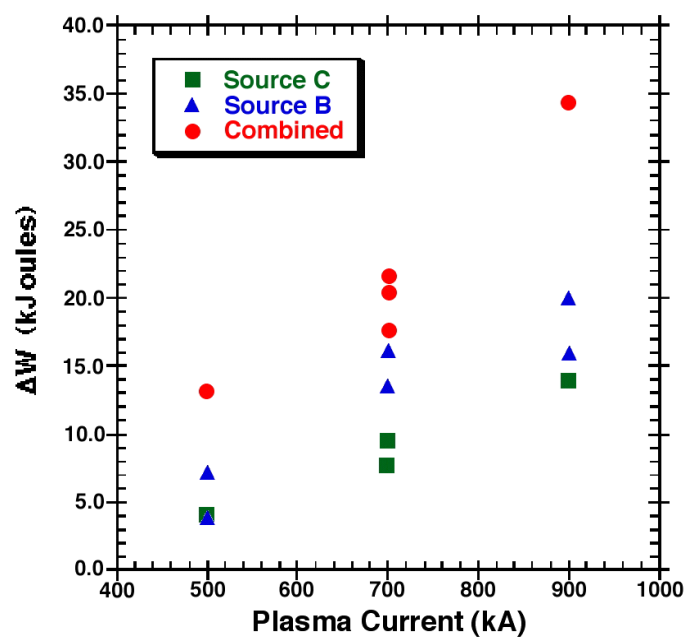

Fig. 17. Incremental Total Stored Energy vs. Plasma Current for ion sources $B$ and $C$ each Providing 1.4 MW.

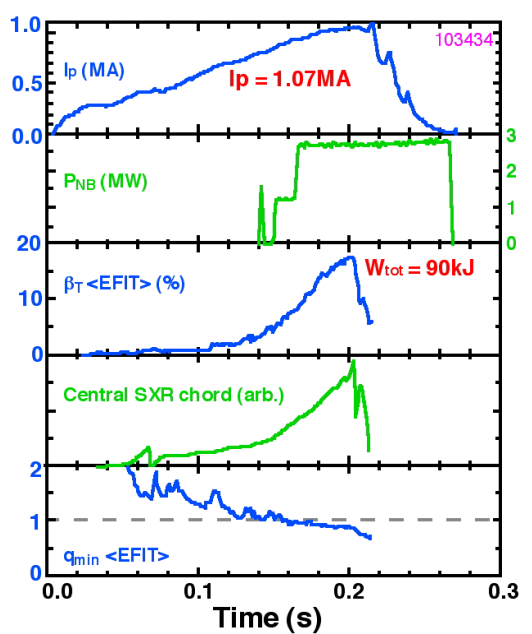

Fig. 18. Time evolution of NBI heated discharge: $B_{T}=3 k G$, Deuterium.

6.2 High Beta Discharges - With the outer two ion sources (B and C) operating at $80 \mathrm{keV}$, the initial NBI plasma heating was investigated utilizing a $\mathrm{P}_{\mathrm{NBI}} \approx 2.8 \mathrm{MW}$. The discharge evolution for a high beta discharge is shown in Fig. 18. As seen in the figure, the plasma current approaches a record value for the $\mathrm{ST}$ of $\approx 1.1 \mathrm{MA}$ peak current with $\mathrm{B}_{\mathrm{T}}=3 \mathrm{kG}$. The total plasma stored energy increases to our record value of $\beta_{\mathrm{T}}=18 \%$, corresponding to $90 \mathrm{~kJ}$ of total plasma stored energy as measured through the EFIT reconstruction. The EFIT 
magnetic reconstruction values have a typical uncertainty of about 20\% [17]. The Troyon normalized beta, $\beta_{\mathrm{N}} \equiv 10^{8} \beta_{\mathrm{T}}$ a $\mathrm{B}_{\mathrm{T}} / \mathrm{I}_{\mathrm{p}}$ is about 3 for this discharge. The EFIT reconstructed plasma poloidal flux contour cross section is shown in Fig. 16. However, around $t=200 \mathrm{~ms}$, the plasma beta collapses as shown in Fig. 18. The central temperature drops rapidly as can been seen with the central soft x-ray channel trace. We observe that prior to the beta collapse, the $n=1 / m=1$ mode is growing and eventually triggers a sawtooth instability, causing this beta collapse. This collapse mechanism is essentially the same as the one observed with ohmic plasmas, as discussed in the previous section. The collapse time correlates well with the $\mathrm{q}_{0}$ going below one, as seen by EFIT. This sawtooth collapse should be avoidable by discharge evolution programming and non-inductive current drive to maintain $\mathrm{q}_{0}$ above 1 . The achievement of $\beta_{\mathrm{T}}$ of $18 \%$ with a relatively small injected power of $2.8 \mathrm{MW}$ is a very encouraging indication of the effectiveness of NBI in obtaining high beta discharges in NSTX.

\section{Summary and Future Plans}

The NSTX facility commenced operation in Feb. 1999. The plasma current was successfully brought up to the design value of 1 MA in a relatively short period in December 1999. All of the planned plasma shaping parameters, $\kappa=1.6-2.2$ and $\delta=0.2-0.4$, were achieved in inner limited, single null and double null configurations. The CHI (Coaxial Helicity Injection) and HHFW (High Harmonic Fast Wave) experiments were also initiated. Using about $27 \mathrm{kA}$ of $\mathrm{CHI}$ injected current, discharges of up to $260 \mathrm{kA}$ toroidal current have been produced from zero current without using the ohmic solenoid. Using twelve antennas connected to six transmitters, HHFW successfully heated electrons, from central temperatures of $400 \mathrm{eV}$ to $900 \mathrm{eV}$, at a central density of $3.5 \times 10^{13} \mathrm{~cm}^{-3}$ (plasma dielectric constant of 40), with about $2.3 \mathrm{MW}$ of HHFW power. The NBI system commenced operation in Sept. 2000. The initial result with two ion sources $\left(\mathrm{P}_{\mathrm{NBI}}=2.8 \mathrm{MW}\right)$ shows good heating, achieving $\beta_{\mathrm{T}} \approx 18 \%$ and a total plasma stored energy of $90 \mathrm{~kJ}$ at $\mathrm{I}_{\mathrm{p}} \approx 1.1 \mathrm{MA}$.

The near-term research program objectives are to bring the NBI and HHFW systems to their full power capability in 2001 (5 MW for NBI and $6 \mathrm{MW}$ for HHFW) and for a $\mathrm{CHI}$ capability of driving $500 \mathrm{kA}$ of non-inductive start-up current in 2002. With these tools, high beta regimes consistent with the no-wall beta limit of about $25 \%$ (with bootstrap current fraction of up to 40\%) will be investigated in the near term (2001-2003). In the longer term (2004 and beyond), more advanced ST regimes will be investigated with active current/pressure profile control (provided by CHI, HHFW, NBI and other tools) and active wall mode stabilization. Development of those plasma control tools is believed to be essential for accessing very advanced ST regimes of steady-state high beta (40\%), high bootstrap fraction $(70 \%)$, and high confinement discharges relevant for the development of an attractive Volume Neutron Source and for future power plants.

\section{ACKNOWLEDGEMENTS:}

We thank the valuable contributions by the NSTX Technical Support Team. The present work is supported by US Dept. of Energy contract No. DE-AC02-76CH03073. 


\section{REFERENCES:}

[1] Y.-K. M. Peng, Phys. of Plasmas 7, (2000) 1681

[2] A. SYKES, et al., Plasma Phys. Contr. Nucl. Fus. Res. 1 (1994) 719.

[3] M. ONO, et al., Plasma Phys. Contr. Nucl. Fus. Res. 2 (1996) 71 (IAEA, 1997).

[4] T. JARBOE, et al., Plasma Phys. Contr. Nucl. Fus. Res. 1 (1994) 725 (IAEA, 1995).

[5] G. REWOLDT, et al., Phys. of Plasmas 3, (1996) 1.

[6] J. MENARD, et al., Nucl. Fusion 37, (1997) 595.

[7] E.T. CHENG, et al., Fus. Eng. and Design 38 (1998) 219.

[8] See for example, R. Stambaugh et al., Plasma Phys. Contr. Nucl. Fus. Res. 3, (1996) 395 (IAEA, 1997). F. Najmabadi et al., and D. C. Robinson et al., (Proc. 17th IAEA F.E. Conf. Yokohama, 1998).

[9] M. ONO, et al., Nucl. Fusion 40 (2000) 557.

[10] S. KAYE, et al., Fus. Tech. 36 (1999) 16.

[11] M. ONO, et al., (Proc. 18 ${ }^{\text {th }}$ IEEE/NPSS SOFE Conf. 1999) 99CH3050, 53.

[12] M. NAGATA, et al., (Proc. $17^{\text {th }}$ IAEA F.E. Conf. Yokohama, 1998), IAEA-CN69/EXP4/10

[13] M. ONO, Phys. of Plasmas 2 (1995) 4075.

[14] C. NEUMEYER et al. and J. CHRZANOWSKI, et al., (Proc. IEEE SOFE Conf. 1999) 99CH3050

[15] D. A. GATES, et al., (Proc. 11th IEEE Conf. Santa Fe, 1999) 278.

[16] R. MAQUEDA and G. WURDEN, Nucl. Fusion 39 (1999) 629.

[17] S. SABBAGH, et al., at this conference.

[18] J. MENARD, et al., at this conference.

[19] S. EJIMA, R. CALLIS, J., LUXON, et al., Nucl. Fus. 22 (1982) 1313.

[20] A. SYKES, et al., at this conference.

[21] R. RAMAN, et al., at this conference.

[22] J. R. WILSON, et al., this conference.

[23] D. S. DARROW, et al., (Proc. 26th EPS Conf. Maastricht, 1999) P4.090. 
The Princeton Plasma Physics Laboratory is operated by Princeton University under contract with the U.S. Department of Energy.

\author{
Information Services \\ Princeton Plasma Physics Laboratory \\ P.O. Box 451 \\ Princeton, NJ 08543
}

Phone: 609-243-2750

Fax: 609-243-2751

e-mail: pppl_info@pppl.gov

Internet Address: http://www.pppl.gov 